\title{
Comunidade Quilombola do Sítio Arruda: organização política, identitária e
}

\section{territorial}

\author{
Quilombola Community of Sítio Arruda: political, identity and territorial organization \\ Comunidad Quilombola de Sítio Arruda: organización política, identidad y territorial
}

Recebido: 04/08/2021 | Revisado: 07/09/2021 | Aceito: 08/09/2021 | Publicado: 10/09/2021

\author{
Tayronne de Almeida Rodrigues \\ ORCID: https://orcid.org/0000-0001-9378-1456 \\ Universidade Federal do Cariri, Brasil \\ E-mail: tayronnealmeid@gmail.com \\ Francisca Laudeci Martins Souza \\ ORCID: https://orcid.org/0000-0003-4211-3233 \\ Universidade Regional do Cariri, Brasil \\ E-mail: laudecimartins@gmail.com \\ Zuleide Fernandes de Queiroz \\ ORCID: https://orcid.org/0000-0003-3174-4750 \\ Universidade Regional do Cariri, Brasil \\ E-mail: zuleidefqueiroz@gmail.com \\ Cicera Nunes \\ ORCID: https://orcid.org/0000-0002-6352-8991 \\ Universidade Regional do Cariri, Brasil \\ E-mail: cicera.nunes@urca.br
}

\begin{abstract}
Resumo
O presente artigo caracteriza do ponto de vista socioantropológico a Comunidade Quilombola do Sítio Arruda. Para tal, realiza-se uma revisão bibliográfica procurando identificar os elementos primordiais de organização social da comunidade, a partir de uma perspectiva histórica. Pretende-se, também, evidenciar os aspectos contemporâneos da vida social da comunidade, apontando as potencialidades e atuais desafios enfrentados. A ocupação tradicional quilombola do Sítio Arruda envolve a migração de 3 (três) famílias de um local conhecido como Sítio Coqueiro, ocorrida em 1983. A reconstituição histórica dos eventos referentes ao contexto de migração é feita a partir das trajetórias das famílias registradas em uma bibliografia de cunho histórico e antropológico (Marques, 2010; Alves, 2018). A vida social contemporânea da comunidade é caracterizada a partir de sua organização política, identitária, de suas manifestações culturais e religiosas. São abordadas as relações dos moradores com o seu território evidenciandose os conhecimentos tradicionais vinculados ao manejo sustentável dos recursos naturais. Por fim, aborda-se as relações de gênero destacando, principalmente, o protagonismo feminino no local, a partir da pesquisa de Felipe (2018) destacando o papel central que as mulheres têm ocupado tanto nos processos políticos de fortalecimento identitário, como nos projetos de geração de renda desenvolvidos na comunidade e nos cuidados com o território.
\end{abstract}

Palavras-chave: Quilombo sítio Arruda; Trajetórias familiares; Direitos territoriais; Protagonismo feminino.

\begin{abstract}
This article characterizes the socio-anthropological point of view of the Quilombola Community of Sítio Arruda. For this, a bibliographical review is carried out, seeking to identify the primary elements of the community social organization, from a historical perspective. It is also intended to show the contemporary social life of the community, compromising potential and challenges faced. The traditional quilombola occupation of Sítio Arruda involves the migration of 3 (three) families from a place known as Sítio Coqueiro, which occurred in 1983. of historical and anthropological nature (Marques, 2010; Alves, 2018). The community's contemporary social life is characterized by its political organization, identity, cultural and religious manifestations. São dealt with the relations of two inhabitants as their own territory, highlighting the traditional knowledge linked to the sustainable management of two natural resources. Finally, gender relations are addressed, mainly highlighting the non-local female protagonism, based on the research by Felipe (2018) highlighting the central role that women have occupied both in the political processes of identity strengthening and in identity projects. community and we are cared for like a land.
\end{abstract}

Keywords: Quilombo sítio Arruda; Family Attire; Territorial guidelines; Female protagonism.

\section{Resumen}

Este artículo caracteriza el punto de vista socio-antropológico de la Comunidad Quilombola de Sítio Arruda. Para ello, se realiza una revisión bibliográfica, buscando identificar los elementos primarios de la organización social 
comunitaria, desde una perspectiva histórica. También pretende mostrar la vida social contemporánea de la comunidad, comprometiendo el potencial y los desafíos enfrentados. La ocupación tradicional quilombola del Sítio Arruda implica la migración de 3 (tres) familias de un lugar conocido como Sítio Coqueiro, que tuvo lugar en 1983. de carácter histórico y antropológico (Marques, 2010; Alves, 2018). La vida social contemporánea de la comunidad se caracteriza por su organización política, identidad, manifestaciones culturales y religiosas. São abordó las relaciones de dos habitantes como su propio territorio, destacando los conocimientos tradicionales vinculados a la gestión sostenible de dos recursos naturales. Finalmente, se abordan las relaciones de género, destacando principalmente el protagonismo femenino no local, a partir de la investigación de Felipe (2018) que destaca el papel central que han ocupado las mujeres tanto en los procesos políticos de fortalecimiento identitario como en los proyectos identitarios. comunidad y nos cuidan como una tierra.

Palabras clave: Quilombo sítio Arruda; Atuendo familiar; Lineamientos territoriales; Protagonismo femenino.

\section{Introdução}

O presente artigo tem como objetivo efetuar uma caracterização socioantropológica da Comunidade Quilombola do Sítio Arruda. A sede da comunidade localiza-se a 17 km de distância da cidade de Araripe, a 24 km da cidade de Campos Sales e a $508 \mathrm{~km}$ da cidade de Fortaleza. Essa região corresponde ao extremo sul do Ceará, na região do Cariri, Chapada do Araripe. Contando, atualmente, com cerca de 65 (sessenta e cinco) famílias, a chegada dos quilombolas no Sítio Arruda envolve a migração de 3 (três) famílias desde um local conhecido como Sítio Coqueiro, ocorrida há cerca de quarenta anos atrás, mais especificamente, em 1983.

As questões norteadoras deste artigo são as relações dos moradores com o seu território, em específico, os processos políticos de fortalecimento identitário e as compreensões que esses moradores articulam a respeito do pertencimento à comunidade quilombola. Também nos atentamos para os conhecimentos tradicionais evidenciados nas formas de viver o território - as formas de manejo dos recursos naturais e os conhecimentos implícitos nessas práticas - para além da subsistência cotidiana. Pretendemos evidenciar algumas dinâmicas da vida social da comunidade a partir de sua organização política e, em específico, do papel central que as mulheres têm ocupado tanto nos processos políticos de fortalecimento identitário, como nos projetos de geração de renda desenvolvidos na comunidade, conforme demonstra a pesquisa de Felipe (2018).

As manifestações culturais e religiosas também serão abordadas como forma de evidenciar as relações dos moradores com o seu território. Por isso, é importante destacar que partimos de um pressuposto conceitual em que a compreensão de território, conforme anunciado por Marques (2010), alude para uma dimensão sociocultural, que diz respeito ao espaço geográfico de um determinado grupo étnico possuidor de uma organização social específica em que a utilização dos recursos naturais ocorre de acordo com as regras de convivência coletiva e tradições culturais. A noção de território também abarca a compreensão de que sua constituição se vincula a um processo histórico de construção de uma identidade social coletiva.

A partir dessa noção de território, Marques (2010) demonstra que no Sítio Arruda a condição quilombola é caracterizada como uma questão de autodefinição coletiva vinculada aos critérios de pertencimento à comunidade, o que assegura aos familiares e seus parentes o direito de permanência no local. Por sua vez, a dinâmica das relações sociais estabelecidas pelos membros da comunidade quilombola podem ser evidenciadas a partir das trajetórias das famílias que vêm ocupando territórios comuns. A fim de efetuar a reconstituição histórica dos eventos referentes a essa ocupação territorial, são retomadas ao longo deste artigo as trajetórias das famílias a partir dos registros disponíveis em uma bibliografia de cunho histórico e antropológico (Marques, 2010; Alves, 2018).

O exercício de trazer à tona as memórias dos moradores, realizado por Marques (2010), Alves (2018) e Felipe (2018), fornecem os registros de uma história marcada pela exploração do trabalho, pelo racismo e pela falta de condições 
mínimas de sobrevivência e pelo protagonismo feminino. Também evidenciam a força da superação, o engajamento político e a afirmação identitária como vetores de transformação de uma dada realidade social.

Considerando o recorte temático, havia o interesse de desenvolver uma pesquisa etnográfica que não foi possível em virtude da Pandemia da COVID-19, ou seja, não adentramos o território para a realização de entrevistas semiestruturadas, observação participante e demais registros com os moradores da comunidade Quilombola Sítio Arruda. Por isso, optamos por realizar uma pesquisa bibliográfica dos trabalhos com um enfoque histórico e antropológico. Conforme Tozoni-Reis (2009), a pesquisa bibliográfica tem como principal característica o fato de que o campo onde é feito a coleta dos dados é a própria bibliografia sobre o tema ou o objeto que se pretende pesquisar em que ocorre o debate com os autores a partir de seus escritos.

Consideramos que a justificativa para uma pesquisa dessa natureza vincula-se ao fato de existirem ainda poucas pesquisas bibliográficas acerca da Comunidade Quilombola do Sítio Arruda, o que, por sua vez, vincula-se, a nosso ver, à histórica e estrutural invisibilidade das comunidades quilombolas, e da população negra, de uma forma mais ampla, no Estado do Ceará.

No mais, acreditamos que a proposta metodológica de pesquisa bibliográfica e documental cumpre com o objetivo geral traçado para o presente artigo, tanto porque há disponibilidade de literatura sobre o tema, quanto porque em um contexto de pandemia de COVID-19 muitas limitações para a prática da pesquisa de campo e até mesmo para a realização presencial de pesquisas documentais (fontes primárias) se impuseram. Em termos de sua estrutura, o presente artigo está organizado em seções dedicadas aos temas acima citados. Ao fim, serão apontadas as considerações finais com a síntese da discussão apresentada.

\section{Metodologia}

Como o objetivo geral do artigo é o de efetuar uma caracterização socioantropológica da Comunidade Quilombola Sítio Arruda, para alcançá-lo optamos por uma metodologia alicerçada nas pesquisas de base bibliográfica e documental, ou seja, de cunho de cunho histórico, antropológico. Tal proposta se sustenta devido a existência de uma literatura, já supracitada, acerca da comunidade que consiste em dissertações (Bispo, 2017), teses (Felipe, 2018; Tavares, 2020) e trabalhos técnicos - em específico, um laudo antropológico, como o realizado por Marques (2010). Em uma consulta realizada na Biblioteca Digital de Teses e Dissertações (BDTD), para além dessas obras sobre a Comunidade Quilombola Sítio Arruda encontramos também, e tão somente, a dissertação de Silva (2017), pesquisa que já foi utilizada por nós em outra oportunidade.

A revisão bibliográfica de tais publicações, que possuem cunho historiográfico e etnográfico, permite tratar das questões norteadoras elencadas acima. Isso porque, tanto a historiografia quanto a realização da etnografia são modalidades de pesquisas qualitativas (cf. Chizzotti, 2003) amplamente utilizadas nos estudos das comunidades quilombolas. Tal argumento pode ser atestado a partir das inúmeras pesquisas disponíveis sobre comunidades quilombolas que articulam a história oral, a historiografia e a antropologia - em específico, a etnografia, que é o campo prático dessa disciplina (cf. Eugenio e Matos, 2020).

\section{Uma Comunidade de Direitos}

O direito constitucional das comunidades remanescentes de quilombos à titulação de seus territórios está previsto no Artigo 68 da Constituição Federal (Brasil, 1988) e foi regulamentado pelo Decreto ${ }^{\circ}$ 4.887, de 20 de novembro de 2003 (Brasil, 2003). O Decreto $\mathrm{n}^{\circ} 4.887 / 03$ define as comunidades remanescentes de quilombos como sendo os grupos étnico- 
raciais, segundo critérios de autodefinição, com trajetória histórica própria, dotados de relações territoriais específicas e com presunção de ancestralidade negra relacionada com a resistência à opressão histórica sofrida.

A legislação supracitada, como pondera Marques (2010), trata do reconhecimento da propriedade coletiva de um território de uso e ocupação tradicional e não da distribuição de lotes individuais de terras a membros de comunidades quilombolas. Isso porque, conforme Marques (2010), para as comunidades quilombolas a terra representa um bem de uso coletivo configurando-se como um elo importante na produção da convivência do grupo, o que garante a sua continuidade no tempo através das gerações. Tal vínculo com o território é fundamental para a preservação da cultura ancestral, ou seja, dos valores e do modo de vida peculiar transmitidos pelos mais velhos.

Foi amplamente demonstrado por Marques (2010) que os moradores da comunidade Sítio Arruda são sujeitos do direito constitucional supracitado ${ }^{1}$. Desde 1983, o Sítio Arruda tornou-se um espaço de acolhida para famílias marcadas pelo sofrimento das relações de exploração de trabalho impetradas pelos grandes proprietários de terra. Alves (2018) argumenta que descendentes de escravizados, oriundos do Sítio Coqueiro, em um local conhecido como Alto dos Grossos, encontraram na permanência no Sítio Arruda um alento para as históricas violações dos direitos humanos que sofreram.

Conforme demonstra Alves (2018), o contexto de formação da comunidade quilombola Sítio Arruda pode ser verificado a partir dos relatos das famílias Nascimento e Caetano de Souza. Em conjunto, esses relatos anunciam a existência da prática da escravização no passado durante suas permanências no Sítio Coqueiro, na fazenda cujo proprietário foi o Sr. Raimundo Barreto da Silva. Trataremos das trajetórias familiares quilombolas na próxima seção. Vejamos.

\subsection{Trajetórias familiares, exploração do trabalho e migração forçada}

A Comunidade Quilombola Sítio Arruda é uma comunidade tradicional negra e rural que se constituiu a partir dos descendentes de três famílias cujos ancestrais foram escravizados. Essas famílias são consideradas famílias-tronco: Nascimento, oriunda de Cabrobó-PE, Caetano de Souza, oriunda de Inhamuns-CE e Pereira da Silva, oriunda da Chapada do Araripe-CE, que, ao longo do tempo, realizaram trocas matrimoniais (Marques, 2010).

Conforme demonstra Marques (2010), os ancestrais das famílias Nascimento e Caetano de Souza, após a Abolição da Escravatura, migraram para a Chapada do Araripe, especificamente, para o Sítio Coqueiro, localizado no município de Araripe-CE. Nessa localidade, passaram, então, a trabalhar para o Cel. Othony Barreto da Silva e para o seu sucessor, Ottoniel Barreto da Silva, irmão, filho de criação e genro do Cel. Othony. As referências dos quilombolas do Sítio Arruda ao Sr. Othony Barreto o retratam como um famoso coronel, grande proprietário de terras, engenhos e gados para quem seus ancestrais trabalharam em um regime de semi-escravidão.

Há uma prova de que houve escravidão no Sítio Coqueiro em um período anterior à chegada no local dos ancestrais das famílias Nascimento e Caetano de Souza. Trata-se de uma escritura de troca de escravos encontrada por Marques (2010) no Cartório do $1^{\circ}$ Ofício de Araripe, datada de 09 de dezembro de 1880, conforme a Figura 1. As terras do Sítio Coqueiro eram de domínio do Sr. Raimundo Barreto da Silva e, por herança, passaram para o Cel. Othony Barreto da Silva e, posteriormente, para Ottoniel Barreto da Silva.

\footnotetext{
1 Peça fundamental de um Relatório Técnico de Identificação e Delimitação (RTID), de acordo com Marques (2010), o Relatório Antropológico elaborado sobre a Comunidade Quilombola Sítio Arruda teve como principal objetivo identificar e propor uma delimitação territorial para as terras ocupadas pela Comunidade Quilombola Sítio Arruda. De acordo com o autor, o estudo baseou-se em um "levantamento da memória oral e documental do grupo no que tange à sua história, suas tradições, seus saberes e suas práticas materiais e simbólicas" (Marques, 2010, p. 05).
} 
Figura 1 - Escritura de troca de escravos.

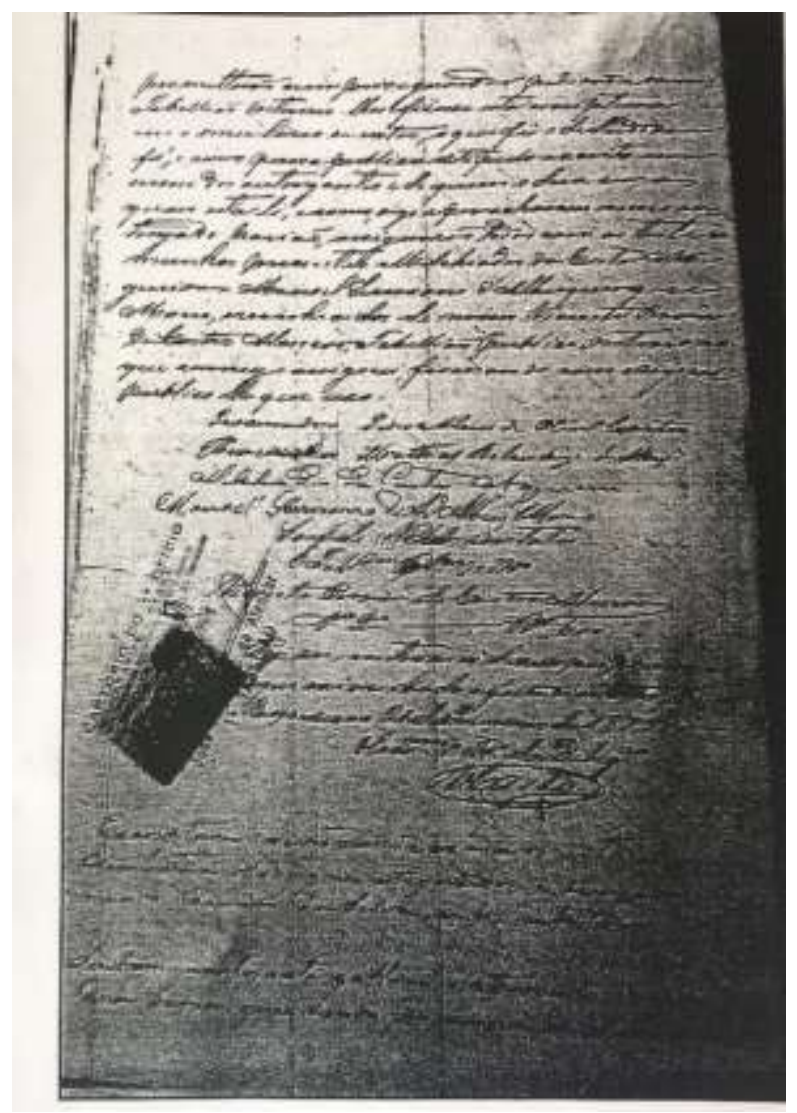

Fonte: Cartório de $1^{\circ}$ Oficio de Araripe - Ceará (1880).

Marques (2010) demonstra que os ancestrais dos quilombolas da Comunidade Sítio Arruda trabalharam por um longo período nas terras do Sítio Coqueiro em regime de parceria com a família proprietária Barreto da Silva. Nesse sistema de trabalho, o proprietário de terras cede uma área para a família do agricultor realizar o plantio em troca de uma parcela do que é produzido na terra.

Com relação à memória coletiva amplamente compartilhada pela Comunidade Quilombola do Sítio Arruda, há uma referência constante a um jovem negro chamado Antônio João do Nascimento, filho ou neto de escravos, que teria migrado, fugindo de um regime de trabalho de semi-escravidão, no início do século XX, do município de Cabrobó-PE para o Sítio Coqueiro. Também conhecido como Antônio Grosso, ele é considerado um tronco genealógico e patriarca dessa comunidade quilombola e se consideram seus parentes consanguíneos ou afins (Marques, 2010).

De acordo com os relatos coletados com os moradores da comunidade quilombola do Sítio Arruda por Marques (2010), o Sr. Antônio João de Nascimento passou a ser considerado "criado" do Cel. Othony Barreto da Silva tendo, posteriormente, se casado com a Sra. Maria Verônica da Conceição - negra e descendente da família quilombola Pereira da Silva. O casal passou, então, a morar com sua família em uma terra recebida por herança pela Sra. Maria Verônica da Conceição, local esse que ficou conhecido como Alto dos Grossos. Em síntese, eis a trajetória da família Nascimento, uma das que compõem a comunidade quilombola do Sítio Arruda.

Já a família Caetano de Souza tem como patriarca o Sr. Caetano Francisco de Souza e matriarca a Sra. Maria Rosalina da Conceição, que foram escravizados pelo Cel. Leandro Feitosa, proprietário da Fazenda Cococi, no município de Parambu-CE, região dos Inhamuns. Uma das filhas desse casal ficou grávida e migrou em busca de melhores condições de vida. Sem condições de criar o seu filho, o entregou aos cuidados do Cel. Ottoniel Barreto do Sítio Coqueiro. Trata-se do Sr. 
Antonio Caetano de Souza, que foi criado como um cativo tendo sido tratado como se fosse um escravo, segundo relato do próprio feito a Marques (2010). O fato é que vários descendentes da família Caetano de Souza se casaram com descendentes da família Nascimento.

Com relação à família Pereira da Silva, Marques (2010) informa que muitas narrativas registradas e também alguns documentos indicam sua origem a partir de pessoas escravizadas pela família branca Barreto da Silva, de quem carregaram o sobrenome Silva. A família branca Barreto da Silva, como citado acima, era uma família escravista tradicional na região do Sítio Coqueiro. Os descendentes da família quilombola Pereira da Silva permaneceram muito tempo trabalhando para as famílias dos descendentes dos senhores de escravos na condição de "negros alforriados".

Marques (2010) explica que, no ano de 1983, as famílias Nascimento e Caetano de Souza, em sua grande maioria, migraram para o Sítio Arruda, também localizado no município de Araripe-CE. Isso porque há cerca de quatro décadas as terras foram vendidas para o Sr. Marcondi Alencar, o que tornou insustentável a permanência dos quilombolas no local, tendo ocorrido a subsequente migração das famílias quilombolas, que deixaram a terra de ocupação tradicional.

As circunstâncias referentes à saída das famílias quilombolas do Sítio Coqueiro envolvem uma verdadeira migração forçada, uma vez que após a compra pelo proprietário Marcondi Alencar as famílias viram suas terras completamente cercadas, sem liberdade de locomoção e sem acesso ao açude. Com tantas pressões, também decidiram vender sua pequena área para esse proprietário.

Com relação às posses de terras no novo local de habitação, Marques (2010) informa que no Sítio Arruda, à época da realização de sua pesquisa para a redação do Relatório Antropológico, apenas algumas famílias possuíam pequenas posses de terras, pois a maioria trabalhava em terras de proprietários brancos em regime de parceria. Tal realidade de ocupação territorial acabava por concentrar todos os moradores numa pequena faixa de terra comprada pelas famílias mais antigas com os recursos das terras tradicionais do Sítio Coqueiro (Alto dos Grossos) vendidas ao Sr. Marcondi Alencar. A sobrevivência nessas terras ocorria a partir da prática da agricultura de subsistência.

A reivindicação territorial da comunidade envolveu a área que os moradores vinham residindo e outros dois imóveis vizinhos. Essa área vizinha já vinha sendo utilizada pelos moradores com a prática da agricultura de subsistência, extração de madeira, caça e coleta de frutos. A área que foi pleiteada corresponde a 334,3401 hectares.

\subsection{Organização política e reivindicação territorial}

A migração a partir do Sítio Arruda para cidades vizinhas e para a região metropolitana de Fortaleza foi uma realidade ante a falta de emprego e condições mínimas de sobrevivência. Isso porque a área ocupada anteriormente à titulação do território quilombola era extremamente pequena. A busca pela escolarização e para acessar serviços de saúde devido à falta de oferta na própria comunidade também foram motivadores dessa saída de moradores. Ante esse cenário adverso, teve início a mobilização pela reivindicação territorial.

Conforme retoma Marques (2010), a organização política com o objetivo de reivindicação territorial foi iniciada na comunidade quilombola Sítio Arruda no ano de 2005. Tal processo envolveu o apoio de alguns órgãos e entidades, como a Associação Cristã de Base (ACB) do município cearense de Crato, o Centro de Referência em Assistência Social (CRAS), a Prefeitura Municipal e o Sindicato dos Trabalhadores Rurais de Araripe e a Câmara Municipal de Salitre, em especial, o então vereador Antônio Silvio Pinto.

O contexto de organização política e identitária contou, inicialmente, com a atuação do CRAS de Araripe. A orientação de uma assistente social foi primordial para que a comunidade alterasse a natureza da associação comunitária passando-se a se identificar como quilombola. $\mathrm{O}$ cadastro dos moradores no CadÚnico como quilombolas realizado pelo 
CRAS garantiu à comunidade maior acesso às políticas de saúde, educação, assistência social e agrícola, como os programas de construção de cisternas e fornecimento de energia elétrica ${ }^{2}$.

A participação de representantes da comunidade em eventos do movimento negro do Cariri, no início de 2007, é apontado por Marques (2010) como um marco na tomada de consciência sobre a identidade étnico-racial da comunidade quilombola Sítio Arruda. Como exemplo desse processo, o autor informa que a Associação Comunitária do Sítio Arruda, criada em 2006, teve seu estatuto alterado, ao fim de 2007, passando a se denominar Associação Quilombola do Sítio Arruda. Em 2008, a Associação Quilombola do Sítio Arruda teve sua utilidade pública reconhecida pela prefeitura municipal de Araripe.

O processo de fortalecimento da identidade étnico-racial da comunidade quilombola Sítio Arruda tem, no ano de 2009, um marco importante com o pedido de certificação junto à Fundação Cultural Palmares. Após a emissão da certidão, a comunidade deu entrada à solicitação de reconhecimento e demarcação de seu território junto ao Instituto de Colonização e Reforma Agrária. Alves (2018) informa que após a demarcação do território no Sítio Arruda ter sido concluída, a comunidade quilombola recebeu a Certidão de Direito Rural de Uso (CDRU) da área de 334,34 hectares em 25 de abril de $2016^{3}$.

\subsection{Autodefinição, pertencimento étnico e territorial}

Marques (2010) argumenta que os moradores quilombolas se auto reconhecem como legítimos herdeiros das terras onde viveram e trabalharam seus ancestrais escravizados e alforriados. Foi essa relação de ex-escravizados e seus descendentes com um território de usufruto coletivo e tradicional a base de constituição de uma comunidade quilombola.

Marques (2010) argumenta que os quilombolas do Sítio Arruda resistiram por muito tempo aos processos de invasão, expropriação e grilagem ocorridos em seus territórios tradicionais no Alto dos Grossos (Sítio Coqueiro). No entanto, o imperativo da migração se impôs e a luta pela ampliação de seus territórios no Sítio Arruda justifica-se como uma compensação das perdas territoriais sofridas no Sítio Coqueiro.

A identificação como quilombola do Sítio Arruda vincula-se, sobretudo, ao reconhecimento como descendentes dos casais fundadores de uma das três famílias (Nascimento, Caetano de Souza e Pereira da Silva). No mais, os quilombolas consideram membros de sua comunidade todas as pessoas que residem na localidade Sítio Arruda - parentes consanguíneos e afins - e também os parentes que não moram na comunidade.

De acordo com Marques (2010), os parentes de fora possuem a prerrogativa do direito territorial e podem estabelecer moradia no Sítio Arruda quando desejarem e assim for aprovado em assembleia pela Associação Quilombola. Já às famílias que não possuem relações de parentesco com os descendentes das famílias Nascimento, Caetano de Souza e Pereira da Silva não foi permitida a permanência na área territorial pleiteada pela comunidade quilombola Sítio Arruda. Os critérios de pertencimento à comunidade são, então, bem definidos: parentesco consanguíneo ou afim com as famílias que deram origem à comunidade, o vínculo formal com participação efetiva na Associação Quilombola do Sítio Arruda e o respeito às regras de boa convivência estabelecidas.

\footnotetext{
2 Tavares (2020) recupera a importância da atuação de um vereador e técnico da Secretaria de Agricultura do município de Araripe, que indicou a comunidade para compor o Programa Um Milhão de Cisternas (P1MC).

${ }^{3}$ Como é possível depreender do processo descrito para o caso do Sítio Arruda, o reconhecimento formal das comunidades quilombolas pelo Estado brasileiro envolve a certificação pela Fundação Cultural Palmares (FCP) e a abertura pelo INCRA) da caracterização da comunidade e produção do Relatório Técnico de Identificação e Delimitação (RTID). Com a publicação do RTID, ocorre a consulta a órgãos e entidades envolvidas no processo e o julgamento das contestações e manifestações contrárias à titulação. De maneira subsequente, é publicada a portaria do presidente do INCRA reconhecendo e declarando os limites das terras do território quilombola e, no caso de haver terceiros no território reconhecido como quilombola, ocorre a desapropriação ou anulação de títulos de posse viciados e reassentamento de posseiros. Por último, ocorre a demarcação física, outorga do título e registro em cartório (Marques e Gomes, 2013).
} 
Quanto aos membros da comunidade que se encontram fora do território por razões de estudo, trabalho e tratamento de saúde é assegurado o pertencimento e os mesmos direitos territoriais dos moradores locais. A saída dos moradores em busca de trabalho é uma realidade presente, e os destinos mais buscados são as cidades vizinhas e a capital Fortaleza. Esse processo de saída do território não implica em um enfraquecimento do pertencimento. Pelo contrário, os parentes que se estabelecem fora acabam construindo uma rede alargada do parentesco marcada pela mobilidade, que se realiza a partir de visitas, trocas de presentes e hospitalidades (Marques, 2010).

Assegurado a todos o direito a um espaço para a construção da residência e uma área para a produção agropastoril familiar, a concepção de um território coletivo para uso comum das famílias quilombolas é uma característica marcante da organização social no Sítio Arruda (Marques, 2010). As situações de conflitos envolvendo reivindicações pelo uso de determinada área, ainda que não recorrentes, contam com a mediação das pessoas mais velhas, que são consultadas pela Associação Quilombola na busca de uma resolução.

\subsection{Conhecimentos tradicionais e manejo do território}

Conforme informa Alves (2018), a maior parte da área do quilombo Sítio Arruda está localizada na zona rural do município de Salitre. No entanto, como parte do território também se localiza no Município de Araripe, os moradores preferem manter suas relações comerciais e acessar serviços educacionais, assistenciais e de saúde nesse município, pois o acesso e a distância favorecem.

A Chapada do Araripe, como toda chapada, é uma formação geológica com uma planície no alto. Especificamente, a Chapada do Araripe se diferencia das por estar em uma região semiárida, e a presença de água em seu entorno faz com que ela ganhe status de oásis. Localizada na divisa dos estados do Ceará, Piauí e Pernambuco, a Chapada do Araripe também abriga uma floresta nacional, uma área de proteção ambiental e um geoparque (Alves, 2018) ${ }^{4}$.

Com relação aos conhecimentos que os quilombolas possuem sobre o seu território, Marques (2010) informa que o grupo o classifica em três unidades de paisagem: área de chapada, área de baixio (vazante) e área de sertão. A área de chapada possui solo arenoso sendo utilizada para a construção das moradias e para a plantação de milho, feijão e mandioca e também para a caça. A área de baixio possui as melhores terras - escuras e férteis, que são utilizadas no período de inverno, de janeiro a abril. Já a área de sertão possui um solo mais seco de coloração avermelhada.

Importante destacar os conhecimentos tradicionais que a comunidade quilombola Sítio Arruda detém a respeito de seu território. Como demonstram Sousa e Fernandes (2016), os moradores do Sítio Arruda praticam diversas formas de preservação da biodiversidade local - rotatividade das áreas de plantio, diversidade de culturas e não utilização de agrotóxicos, por exemplo - que resultam no equilíbrio ecológico. Isso demonstra que os conhecimentos tradicionais estão intimamente relacionados com a preservação do meio e, nesse sentido, o resgate, a proteção e a valorização desses conhecimentos constituise como estratégia eficaz para a conservação da biodiversidade.

No território Quilombola Sítio Arruda há três tipos de vegetação: uma vegetação de caatinga, que predomina na área do sertão, uma vegetação de floresta, que predomina em toda a área de chapada e uma vegetação de vazantes, que se encontra na área do baixio (Alves, 2018). Parte do acesso à água para consumo humano na comunidade quilombola Sítio Arruda é

\footnotetext{
${ }^{4}$ A Chapada do Araripe é um acidente geográfico, com altitude máxima de cerca de 1000m, e sítio paleontológico localizado na divisa dos Estados do Ceará, Pernambuco e Piauí, no Brasil. A chapada abriga uma floresta nacional (1946), uma área de proteção ambiental (1997) e um geoparque (2006). Existem dois tipos principais de solo: latossolo e sedimentar. O primeiro, oriundo do períodocretáceo, é rico em fósseis. Já a bacia sedimentar se caracteriza por formar aquíferos, existindo várias fontes de água espalhadas por toda a área da chapada. A fauna local é composta por diversas espécies de répteis, insetos e mamíferos. A vegetação predominante é de cerradão. Existem faixas de transição que apresentam traços de mata atlântica, cerrado e caatinga. O clima é semiárido, com baixa e concentrada pluviosidade (Lima et $a l, 2012$ ).
} 
garantida pelas cisternas de polietileno, com capacidade para 16 mil litros, que foram distribuídas pelo Programa Água para Todos, a partir de $2014^{5}$.

O vínculo com a terra é um elemento central na dinâmica social da comunidade quilombola do Sítio Arruda. A agricultura de subsistência tem no milho e no feijão suas principais lavouras, ao lado da mandioca. A divisão social do trabalho possui um recorte de gênero em que as atividades que demandam mais força são realizadas pelos homens, como fazer cercas. As mulheres se encarregam de plantar, colher e beneficiar os produtos conforme Figura 2. Já o cuidado com os animais pode ser compartilhado por ambos os gêneros.

Figura 2 - Mulheres debulhando fava.

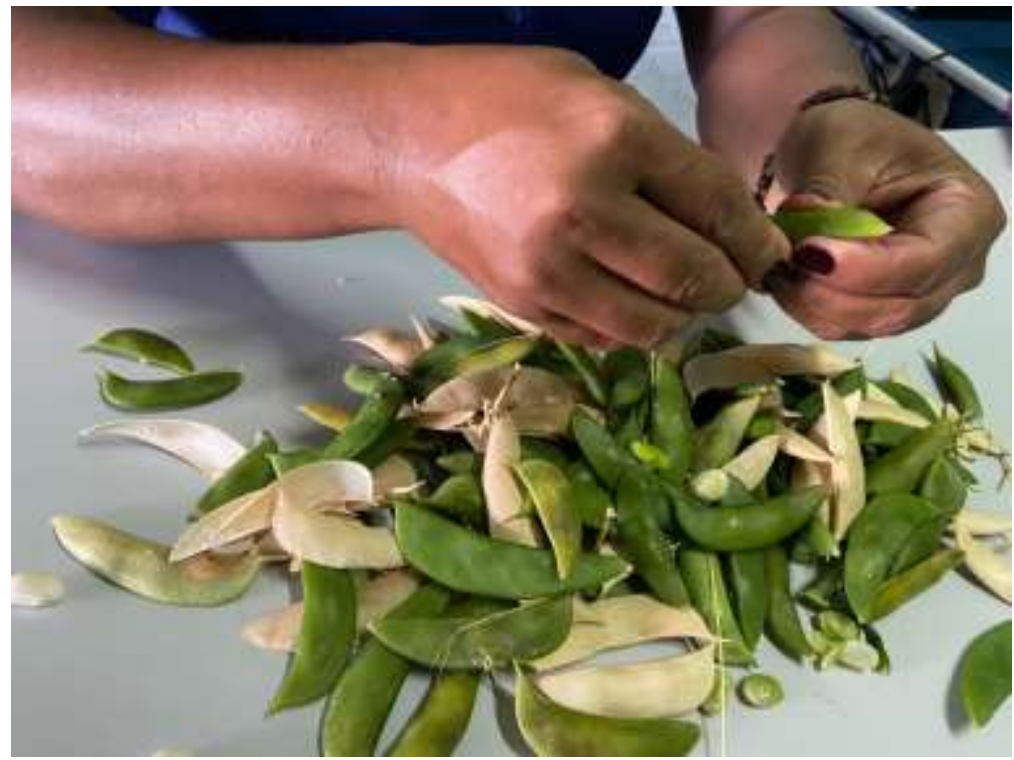

Fonte: Dados da pesquisa (2021).

\subsection{Manifestações culturais e religiosidade}

Com relação às tradições culturais e religiosas herdadas dos ancestrais, Marques (2010) argumenta que houve um desaparecimento devido à morte de alguns líderes antigos, da migração e crescente desinteresse. Dentre essas tradições, destacavam-se cantos fúnebres, como benditos e incelenças e banda de pifes. Práticas de rituais da religião Umbanda também foram abandonadas.

Alves (2018) afirma que os moradores da comunidade quilombola Sítio Arruda se auto definem como católicos. A comunidade encontrou ao longo do tempo algumas dificuldades para a prática religiosa por não ter um local adequado. No entanto, a construção da capela de Nossa Senhora Aparecida foi concluída há alguns anos atrás e se localiza bem próxima à Associação Quilombola do Sítio Arruda.

Alves (2018) argumenta que os moradores da comunidade quilombola Sítio Arruda são alegres e festivos. Como exemplo, cita as participações dos comunitários nas festas de Padroeiro, renovação e novenário, eventos nos quais as Bandas Cabaçais $^{6}$ se apresentam. $\mathrm{O}$ autor também destaca o mês de outubro no calendário ritual da comunidade devido às nove noites de novenas para Nossa Senhora Aparecida. Finalizado com um leilão acompanhado por comidas típicas, durante as

\footnotetext{
${ }^{5}$ Importante observar que essas cisternas não se tratam daquelas implementadas pelo Programa 1 milhão de Cisternas, conforme nota 2.

${ }^{6}$ De acordo com Alves (2018), a Banda Cabaçal, ou Banda de Couro, Banda de Pífanos ou apenas Cabaçal é o conjunto musical mais típico do interior cearense e da região caririense. Tradicionalmente formada pelos instrumentos zabumba, pífaros e uma caixa, atualmente tem se utilizado também os pratos.
} 
nove noites as mulheres cantam benditos - canções religiosas executadas nos pífanos e acompanhadas por instrumentos de percussão. No dia 12 de outubro, também ocorre uma procissão na qual a imagem de Nossa Senhora percorre toda a comunidade.

Alves (2018) também observa que alguns festejos tradicionais, terços, velórios e sentinelas são praticados nas casas dos moradores. Outro ritual fora das dependências da Igreja ocorre no dia 02 de novembro, dia de Finados, em que as mães se reúnem no cemitério dos Anjinhos para ornamentar e colocar flores nos túmulos de seus filhos, que morreram antes de serem batizados.

Dentre os rituais praticados na comunidade quilombola do Sítio Arruda, Alves (2018) também se destacam as orações, benditos, incelências e outros cantos fúnebres realizados durante os velórios. Resultado da fusão de culturas de matriz portuguesa, africana e indígena, o autor explica que as incelências são cantos entoados em velórios e também em sentinelas. As sentinelas são realizadas para que os doentes possam recuperar a sua saúde e também para que os desenganados sejam purificados de seus pecados e suas almas sejam encaminhadas aos anjos e santos.

Alves (2018) também menciona a utilização do que os quilombolas denominam de orações fortes e que identificam como uma herança cultural dos antepassados, os videntes e curandeiros. À época de sua pesquisa, Alves (idem) identificou que o quilombola vivo mais idoso, o Sr. Enoque Nascimento, com noventa e sete anos, era conhecido como alguém com o poder de curar e aconselhar pessoas com problemas espirituais.

Ao encontro do que argumenta Marques (2010), Alves (2018) aponta que na comunidade quilombola do Sítio Arruda parece ocorrer um crescente desinteresse dos jovens pelas festividades tradicionais. Como exemplo, o autor cita que as festas de reisado, famosas no passado, se findaram por falta de tocadores.

\subsection{O protagonismo das mulheres no Sítio Arruda}

Um elemento de destaque na dinâmica social da comunidade quilombola Sítio Arruda diz respeito ao protagonismo assumido pelas mulheres na condução de temas importantes para o local. É nesse sentido que Felipe (2018) apresenta as mulheres da comunidade quilombola Sítio Arruda evidenciando suas práticas cotidianas. Tal apresentação é feita a partir do registro dos relatos das moradoras. A autora destaca a polivalência dessas mulheres e sua importância nas conquistas da comunidade.

As mulheres tiveram um papel central no processo de fortalecimento político do Sítio Arruda. Isso é evidenciado nas memórias registradas por Felipe (2018). Uma de suas interlocutoras relembra que foram as mulheres que iniciaram a busca pelas informações sobre os antepassados, ação que se relacionou ao início da constituição da Associação Quilombola no local.

As atividades rotineiras efetuadas pelas mulheres envolvem os cuidados com a casa, com a educação dos filhos e no manejo dos animais de pequeno e médio porte - porcos, carneiros e galinhas. Como dito na seção 3.2, as mulheres também desempenham atividades centrais na produção dos alimentos, pois são responsáveis pelo plantio, colheita e beneficiamento.

As mulheres também se dedicam à confecção de bordado de crochê vendidos nas feiras regionais. De acordo com Felipe (2018), essa atividade contou com o apoio do Programa Paulo Freire e financiamento do Fundo Internacional de Desenvolvimento Agrícola (FIDA), conforme a Figura 3. As mulheres também participam de outro projeto do Programa Paulo Freire, que se trata de uma horta irrigada que envolveu a capacitação das moradoras e contribui com a produção de alimentação de alto valor nutritivo conforme figura 4. 
Research, Society and Development, v. 10, n. 11, e553101120245, 2021

(CC BY 4.0) | ISSN 2525-3409 | DOI: http://dx.doi.org/10.33448/rsd-v10i11.20245

Figura 3 - Artesanatos produzidos na Comunidade.

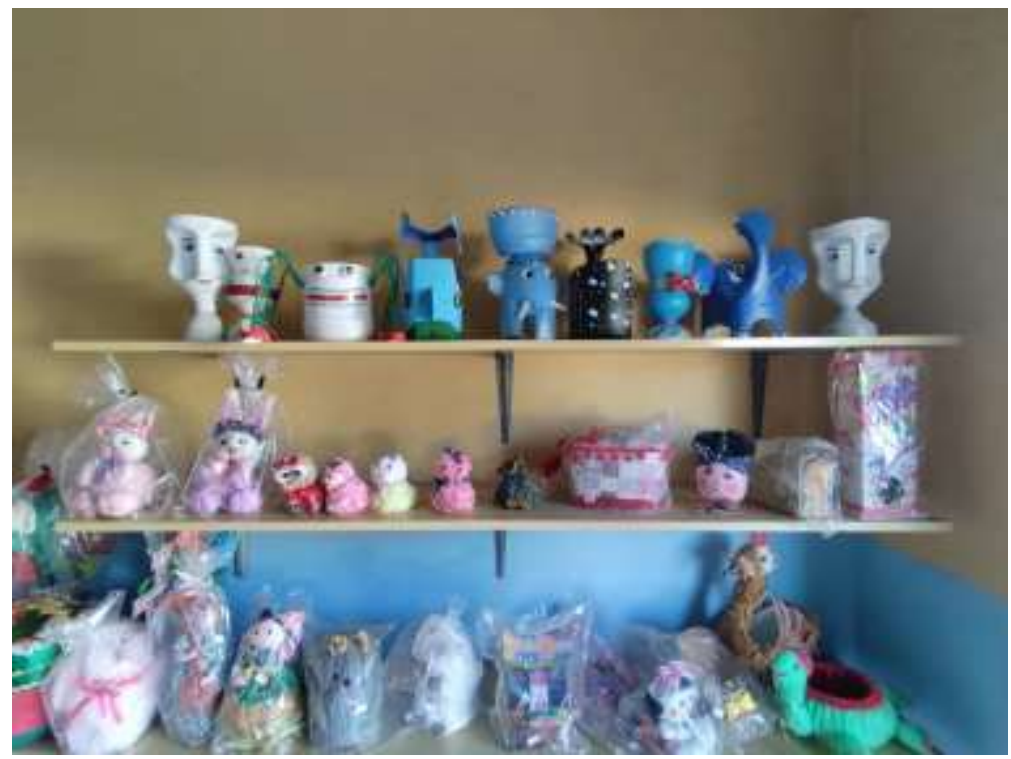

Fonte: Dados da pesquisa (2021).

Figura 4 - Horta da Comunidade.

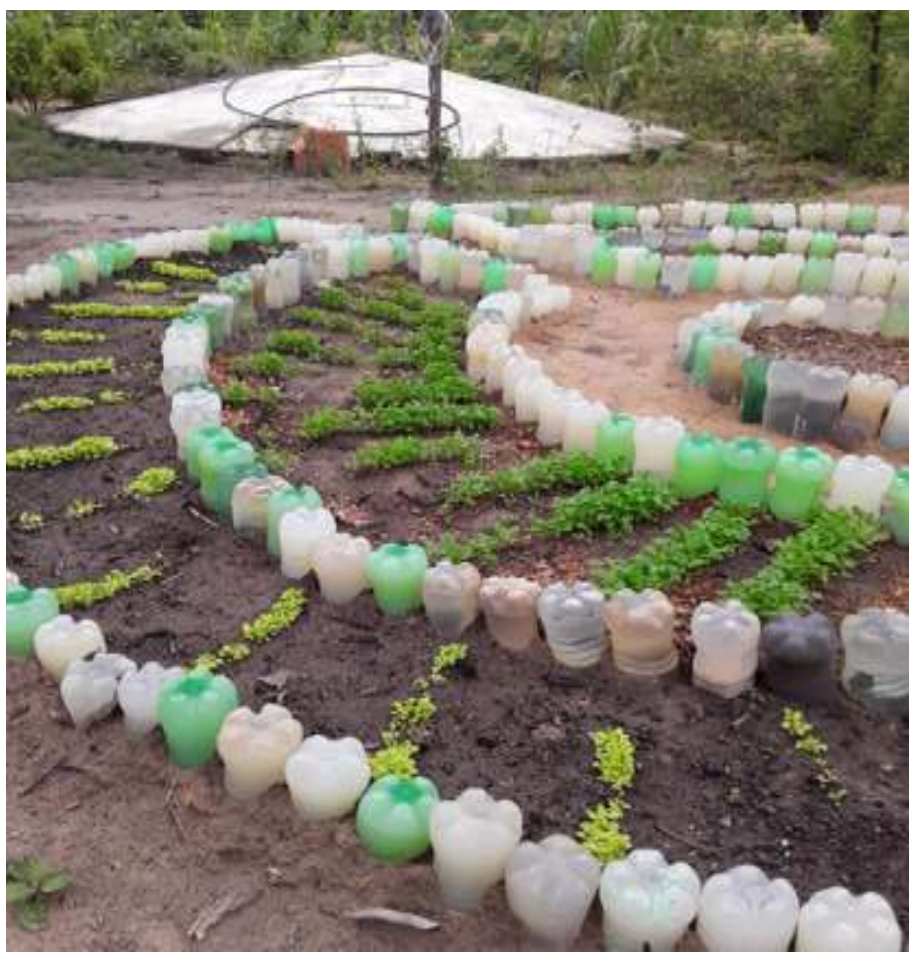

Fonte: Dados da pesquisa (2021).

A comunidade quilombola Sítio Arruda também foi beneficiada pelo Projeto Zumbi coordenado pelo Instituto de Desenvolvimento Agrário do Ceará/IDACE. Esse projeto envolveu a compra de máquinas de costura, ferros industriais, tesouras e matéria prima para confecção. Na avaliação de Felipe (2018), os projetos contribuem para o desenvolvimento da comunidade e possibilitam que as mulheres gerem renda extra aumentando sua autonomia. 
Felipe (2018) argumenta que as mulheres são as verdadeiras guardiãs das memórias da comunidade. A autora realizou entrevistas com as mulheres da comunidade que possuem importantes conhecimentos da tradição quilombola. Foram registrados pela autora diversos relatos de mulheres, como a rezadeira Dona Francisca Claudina; a anciã mais velha, a Dona Raimunda Veronica do Nascimento; a parteira Dona Antônia Pereira e a também parteira e raizeira Dona Lúcia Lourenço, que possui um quintal com muitas plantas medicinais conforme Figura 5.

Figura 5 - Quintas com as plantas medicinais.

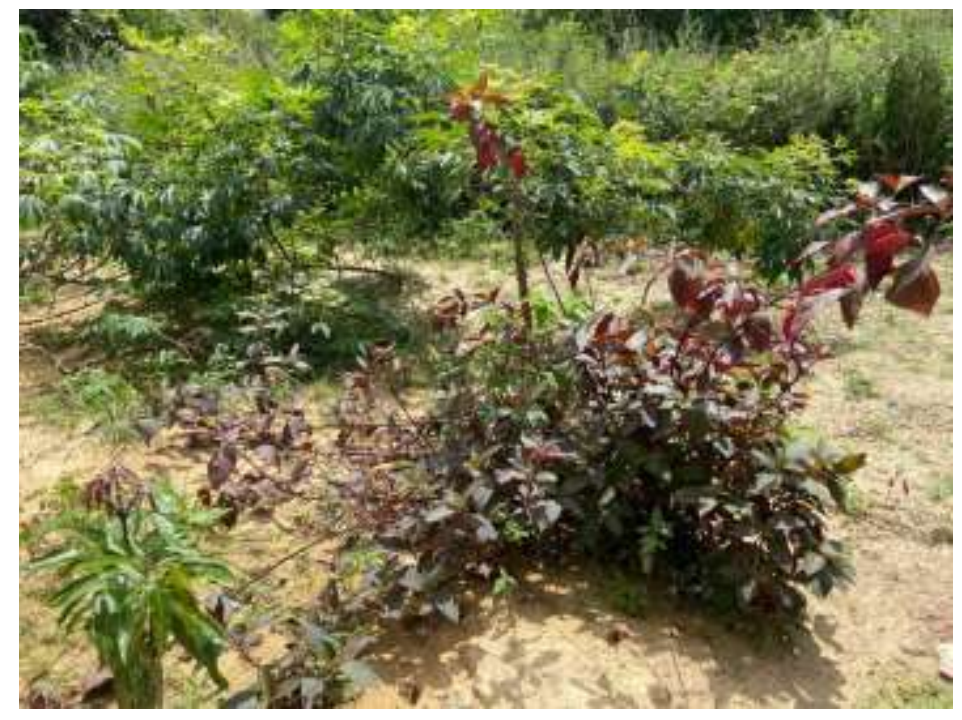

Fonte: Dados da pesquisa (2021).

Bispo (2017), que em sua pesquisa entrevistou mulheres consideradas referências no conhecimento de plantas medicinais, demonstra que o cultivo dessas plantas é realizado nos quintais das casas com extrema dedicação e cuidado. Isso envolve, por exemplo, garantir a irrigação em um ambiente marcado pela dificuldade no acesso à água. Demais plantas medicinais, como árvores de grande porte, são mantidas próximas às casas, como o eucalipto, a aroeira do sertão e o cedro.

Bispo (2017) também demonstra que os conhecimentos tradicionais sobre as plantas medicinais também vinculam-se às formas de elaboração dos preparados terapêuticos - chás, infusões, banho, xarope, dentre outros. Esses preparados terapêuticos são feitos a partir de diversas partes das plantas, como a raiz, a entrecasca, o fruto, a semente, a casca ou a planta inteira. Os conhecimentos são transmitidos pelos mais velhos em um regime de herança dentro de uma tradição familiar. Essa tradição familiar é o que garante que seja mantido o cultivo das plantas nativas e a retirada, através do extrativismo, das espécies do bioma local, a caatinga.

Ainda com relação ao protagonismo feminino, Felipe (2018) também destaca a moradora Fátima Lourenço, que, à época, era secretária da Associação e a liderança feminina mais nova da comunidade. A autora argumenta que as narrativas das mulheres da comunidade quilombola do Sítio Arruda tratam de uma história de discriminação racial e da luta pelo acesso às políticas públicas. É destacada também a coragem das mulheres no enfrentamento das dificuldades, assim como a união e o espírito de solidariedade são evidenciados nos relatos das moradoras.

As memórias das mulheres do Sítio Arruda registradas por Felipe (2018) também tratam do processo de autodefinição como quilombolas. Parte desse processo vinculou-se com o envolvimento nas agendas coletivas de luta por conquista de direitos. A autora também argumenta que o reconhecimento como comunidade quilombola teve um efeito positivo com relação à valorização e visibilidade da comunidade. 
Sob a responsabilidade das mulheres encontram-se as atividades relacionadas desde à Associação Quilombola à igreja. Com relação às mulheres entrevistadas por Felipe (2018), a autora identifica as atividades principais de cada uma delas. Dona Claudina, por exemplo, é uma rezadeira a quem é atribuído um grande poder de cura. A importância atribuída às rezas na comunidade vincula-se, de acordo com a autora, à resolução de problemas de saúde e espirituais. A utilização de chás, garrafadas e banhos compõem o arsenal utilizado pelas rezadeiras. Felipe (2018) também destaca a atividade de parteira. As parteiras possuem conhecimentos e experiências acumulados ao longo dos anos que envolvem também o domínio sobre rezas, benzimentos, banhos e o uso de simpatias.

O protagonismo feminino na comunidade quilombola Sítio Arruda tem se vinculado intimamente com a participação das mulheres nos processos de fortalecimento político. Felipe (2018), destaca que essa participação ativa foi fundamental para as conquistas na comunidade. As mulheres também são portadoras de práticas de saúde, como descrito acima, e detém um vasto arcabouço de conhecimentos que são transmitidos geração a geração.

Felipe (2018) argumenta que há na comunidade uma preocupação com as mulheres jovens, devido, principalmente, à falta de oportunidades de empregos formais e o casamento precoce. A inserção dessas jovens mulheres em atividades que possam gerar renda, assim como a educação para o planejamento familiar, têm se configurado entre as necessidades urgentes da comunidade.

\section{Considerações Finais}

Os quilombolas do Sítio Arruda ocuparam de forma tradicional durante mais de 100 (cem) anos uma área de terra conhecida como Alto dos Grossos, situada no entorno do Sítio Coqueiro, no município de Araripe. Em virtude de pressões dos novos proprietários do Sítio Coqueiro e da falta de condições objetivas para sobrevivência do grupo, as famílias quilombolas resolveram vender sua pequena faixa de "terras de herança" que lhe restavam no Alto dos Grossos e migraram para uma localidade conhecida como Bolandeira dos Estevãos, onde compraram uma nova área de terra que passaram a chamar de Sítio Arruda, local onde estão vivendo atualmente.

Tavares (2020) demonstra que no contexto histórico mais amplo da região do Cariri, durante o século XX, ocorreu a expansão da criação de gado, o que provocou conflitos territoriais com a expulsão de muitas famílias de seus locais de ocupação. Desterritorializados, grupos familiares se deslocaram para regiões mais isoladas, o sertão do semiárido, as áreas mais elevadas da Chapada do Araripe. Nessa região, marcada pela dificuldade de acesso à água e baixa qualidade da terra, famílias pretas e pardas teriam encontrado refúgio ante à expansão pecuária em curso comprando porções de território de baixo valor. Eis o caso da comunidade quilombola Sítio Arruda descrito neste artigo.

A origem da comunidade quilombola do Sítio Arruda e das comunidades quilombolas na região do Cariri não foi diferente do restante do Brasil e vincula-se, principalmente, às históricas injustiças sociais decorrentes da falta de acesso à terra, que, sobre a população negra, possui um caráter ainda mais evidente. Por sua vez, o contexto de reivindicação por direitos, apesar de histórica, assume particular destaque, ao final da década de 1980, com a garantia constitucional dos direitos territoriais.

A Comunidade Quilombola Sítio Arruda possui muitos conhecimentos tradicionais que, por sua vez, estão diretamente vinculados às práticas e saberes pautados no cuidado com os recursos disponíveis em seu território. Os conhecimentos tradicionais compõem um rico patrimônio cultural imaterial que faz parte da identidade da comunidade.

Importante destacar o Projeto de Mapeamento das Comunidades negras do Cariri realizado a partir da articulação do Grupo de Valorização Negra do Cariri (GRUNEC) e pela Cáritas Diocesana do Crato (GRUNEC e Cáritas Diocesana do 
Crato, 2011). Iniciativas dessa natureza contribuem de maneira muito significativa para que a invisibilidade, a desinformação e o preconceito ainda tão presente em parte da sociedade cearense seja, de uma vez por todas, superada.

Historicamente, as comunidades quilombolas no Ceará têm ocupado terras com baixa produtividade, sofrem com a escassez de água e ainda não têm garantida uma educação contextualizada. Por outro lado, também é verdade que nas últimas décadas outra história tem sido escrita, uma história dos oprimidos que a partir do fortalecimento identitário conquistou direitos até então negados. O protagonismo feminino tão presente nas comunidades quilombolas vincula-se, sobretudo, ao fato de que um quilombo representa um agrupamento familiar, ou, como bem definido pelo GRUNEC (2011), um agrupamento de vida. E se cuidar do território é uma forma de cuidar da mãe-terra, eis que as mulheres do Sítio Arruda vêm ensinando os fundamentos principais dessa importante lição.

\section{Referências}

Alves, J. W. F. (2018). A emergência das comunidades quilombolas como fenômeno político no Ceará: Sítio Arruda, no município de Araripe. Tese de Doutorado, UniSinos, São Leopoldo, RS, Brasil.

Brasil.(1988). Constituição da República Federativa do Brasil. Brasília, DF: Senado Federal: Centro Gráfico. https://www2.senado.leg.br/bdsf/bitstream/handle/id/518231/CF88_Livro_EC91_2016.pdf.

Brasil. (2003). Presidência da República. 2003. Decreto $n^{\circ} 4.887$, de 20 de novembro de 2003. Regulamenta o procedimento para identificação, reconhecimento, delimitação, demarcação e titulação das terras ocupadas por remanescentes das comunidades dos quilombos de que trata o art. 68 do Ato das Disposições Constitucionais Transitórias. http://www.planalto.gov.br/ccivil_03/decreto/2003/d4887.htm.

Bispo, G. L. (2017). Plantas medicinais na comunidade quilombola Arruda, Araripe-CE: conhecimento e sustentabilidade. Dissertação de Mestrado, Universidade Federal do Cariri, Juazeiro do Norte, CE, Brasil.

Cunha Junior, H. (2006). Metodologia afrodescendente de pesquisa. Texto de trabalho na disciplina de Educação Gênero e Etnia na perspectiva dos Afrodescendentes. http://afrodescendentes-sjb.blogspot.com.br/p/medologia-afrodescendente-de-pesquisa.html.

Chizzotti, A. (2003). A pesquisa qualitativa em ciências humanas e sociais: evolução e desafios. Revista Portuguesa de Educação, 16 (2), 221-236. https://www.redalyc.org/articulo.oa?id=37416210.

Eugenio, B., \& Matos, W. S. (2020). Pesquisa e produção de conhecimento sobre quilombos: entrevista com José Maurício Arruti. ODEERE: Revista do Programa de Pós-Graduação em Relações Étnicas e Contemporaneidade, 5(9), 23-48. https://doi.org/10.22481/odeere.v5i9.6881.

Felipe, M. L. F. M. (2018). O protagonismo feminino: Comunidade Quilombola Sítio Arruda em Araripe - Ceará. Tese de Doutorado, UniSinos, São Leopoldo, RS, Brasil.

Grupo de Valorização Negra do Cariri (GRUNEC); \& Cáritas Diocesana do Crato. (2011). Caminhos: Mapeamento das Comunidades Negras e Quilombolas do Cariri Cearense. Crato: GRUNEC; Cáritas Diocesana do Crato.

Lima, G. G.; Silva, O. G.; Ribeiro, S. C.; \& Souza, J. O. P. (2012). Mapeamento de unidades geomorfológicas da bacia do rio Salamanca, Cariri Cearense. IX SINAGEO: Simpósio Nacional de Geomorfologia. Rio de Janeiro. http://www.sinageo.org.br/2012/trabalhos/8/8-700-62.pdf.

Leandro Neto, J.; \& Rodrigues, T. A. (2019). História e memória da Comunidade Quilombola do Sítio Arruda em Araripe - CE. Revista África e Africanidades,

Quissamã, $1-4$ https://africaeafricanidades.online/documentos/32/colunistas/Hist\%C3\%B3ria\%20e\%20mem\%C3\%B3ria\%20da\%20Comunidade\%20Quilombola\%20do\%20 S\%C3\%ADtio\%20Arruda\%20em\%20Araripe\%20\%E2\%80\%93\%20CE.pdf.

Marques, J. G. (2010). Relatório Antropológico de reconhecimento e delimitação do território da Comunidade Quilombola Sítio Arruda. Fortaleza: INCRA/SR-02/F/F4 CE.

Marques, C. E.; \& Gomes, L. (2013). A Constituição de 1988 e a ressignificação dos quilombos contemporâneos: limites e potencialidades. Revista Brasileira de Ciências Sociais, 28, (81).

Ratts, A. (2016). A diferença negra e indígena no território: observações acerca de Fortaleza e do Ceará. Geosaberes, Fortaleza, 7, (12), 03-16. https://doi.org/10.26895/geosaberes.v7i12.527.

Matias, E. F.; Silva, S. P. S.; \& Ribeiro, R. M. B. (2019). Caminhos Negros no Ceará: Identidades de Resistências. Id on Line Rev.Mult. Psic., 13, (46), 379391. 10.14295/idonline.v13i46.1892.

Santos, A. P.; \& Cunha Junior, H. (2019). Experiência educativa em comunidade quilombola caririense: pedagogia de quilombo. Debates em Educação, 11, (23), 584-587.

Silva, M. E. (2017). História, memória e identidade quilombola no Cariri-cearense (Comunidades Sítio Arruda - Araripe e Carcará-Potengi. Dissertação de Mestrado, Universidade Federal da Paraíba, João Pessoa, PB, Brasil. https://repositorio.ufpb.br/jspui/handle/123456789/11901?locale=pt_BR. 
Research, Society and Development, v. 10, n. 11, e553101120245, 2021

(CC BY 4.0) | ISSN 2525-3409 | DOI: http://dx.doi.org/10.33448/rsd-v10i11.20245

Sousa, G. M. \& Fernandes, G. P. (2016). Caracterização geoambiental da comunidade quilombola Sítio Arruda em Araripe-CE. Cadernos de Estudos Geoambientais - CADEGEO, 07, (01), 45-55.

Tavares, G. O. (2020.) Territorialidades e identidades Quilombolas em questão na Chapada do Araripe - Cariri, Ceará. Tese de Doutorado, Universidade de Brasília, Brasília, DF, Brasil. https://repositorio.unb.br/handle/10482/40432.

Tozoni-Reis, $\quad$ M. $\quad$ F. $\quad$ C. $\quad$ (2009). Metodologia da Pesquisa. $\quad$ Curitiba: IESDE https://biblioteca.isced.ac.mz/bitstream/123456789/785/1/METODOLOGIA\%20DA\%20PESQUISA.pdf. 